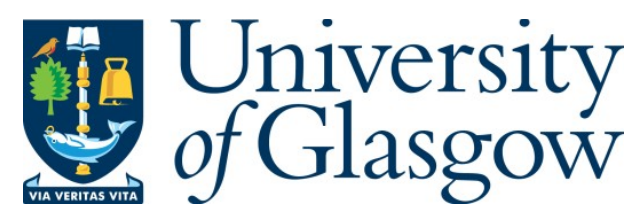

Samuel, N. A., Cuthbert, J. J., Brown, O. I., Kazmi, S., Cleland, J. G.F., Rigby, A.

S. and Clark, A. L. (2021) Relation between thyroid function and mortality in patients with chronic heart failure. American Journal of Cardiology, 139, pp. 57-63.

(doi: 10.1016/j.amjcard.2020.10.034)

This is the Author Accepted Manuscript.

There may be differences between this version and the published version. You are advised to consult the publisher's version if you wish to cite from it.

$\underline{\text { https://eprints.gla.ac.uk/226180/ }}$

Deposited on: 25 November 2020

Enlighten - Research publications by members of the University of Glasgow http://eprints.gla.ac.uk 


\section{The Relation between Thyroid Function and Mortality in patients with Chronic Heart}

\section{Failure}

Nathan A. Samuel,,$^{1 *}$ Joseph J. Cuthbert, ${ }^{2}$ Oliver I. Brown, ${ }^{2}$ Syed Kazmi, ${ }^{2}$ John G. F. Cleland, ${ }^{3}$ Alan S. Rigby, ${ }^{1}$ Andrew L. Clark. ${ }^{2}$

${ }^{1}$ Hull York Medical School, University of Hull, UK

${ }^{2}$ Department of Academic Cardiology, Hull York Medical School, Hull and East Yorkshire Medical Research and Teaching Centre, Castle Hill Hospital, Cottingham, Kingston upon Hull, UK

${ }^{3}$ Robertson Institute of Biostatistics and Clinical Trials Unit, University of Glasgow, Glasgow, UK

\section{Corresponding Author}

Nathan A. Samuel, Department of Academic Cardiology, Hull York Medical School, Hull and East Yorkshire Medical Research and Teaching Centre, Castle Hill Hospital, Cottingham, Kingston upon Hull UK

Tel: +441482461776

Fax: +44 1482461776

Email: hyns8@hyms.ac.uk

\section{Declarations of Interest}

None. 


\section{ABSTRACT}

\section{Objectives}

Thyroid dysfunction is common in patients with chronic heart failure (CHF), but there is conflicting evidence regarding its prognostic significance. We investigated the relation between thyroid function and prognosis in a large, well characterised cohort of ambulatory patients with CHF.

\section{Methods}

Heart failure was defined as signs and symptoms of the disease and either left ventricular systolic dysfunction (LVSD) mild or worse (heart failure with reduced ejection fraction (HeFREF)), or no LVSD and raised amino-terminal pro-B-type natriuretic peptide (NT-proBNP) levels (>125 ng/L) (heart failure with normal ejection fraction (HeFNEF)). Euthyroid state was defined as a thyroid stimulating hormone (TSH) level between 0.35-4.70 mIU/l, hypothyroidism as TSH >4.70 mIU/L, and hyperthyroidism as TSH $<0.35 \mathrm{mIU} / \mathrm{L}$.

\section{Results}

2997 patients had HeFREF and 1995 patients had HeFNEF. 4491 (90\%) patients were euthyroid, 312 (6\%) were hypothyroid, and 189 (4\%) were hyperthyroid. In univariable analysis, both hypothyroid patients (hazard ratio (HR) 1.25, 95\% confidence interval (CI) 1.08 to 1.45) and hyperthyroid patients (HR $1.21,95 \%$ CI 1.01 to 1.46) had a greater risk of death compared to euthyroid patients. There was a U-shaped relation between TSH and outcome. Increasing TSH was a predictor of mortality in univariable analysis (HR 1.02, 95\% CI 1.01 to 1.03), but the association disappeared in multivariable analysis. The three strongest predictors of adverse outcome were increasing age, increasing NTproBNP, and higher NYHA class.

\section{Conclusion}

Although thyroid dysfunction is associated with worse survival in patients with CHF, it is not an independent predictor of mortality.

Key words: TSH, heart failure, thyroid, hypothyroidism 


\section{INTRODUCTION}

Thyroid hormones have genomic and non-genomic effects on the cardiovascular system.(1) They increase stroke volume, heart rate, and reduce systemic vascular resistance.(2) Overt thyroid disease (both hypothyroidism and hyperthyroidism) can cause heart failure.(3) Subclinical thyroid dysfunction is present when serum thyroid stimulating hormone level (TSH) is outside the reference range, but free thyroxine (fT4), and total or free triiodothyronine level (T3) are normal.(4) In subclinical hyperthyroidism (SHyper), TSH is low, and in subclinical hypothyroidism (SHypo), TSH is raised.

Thyroid dysfunction is common in the elderly and is more common in women than men.(5) SHypo is associated with an approximate doubling in risk of coronary heart disease,(6) stroke,(7) and heart failure.(8) SHyper is associated with increased risk of rhythm disturbances, such as atrial fibrillation (AF).(9) The reported average yearly progression rate from subclinical to overt thyroid disease ranges from 2 to $6 \%,(1)$ and the risk of progression is higher in patients with anti-thyroid peroxidase antibodies.(10)

Studies reporting the relationship between thyroid dysfunction and outcomes in large populations of patients with heart failure have produced conflicting results. Most studies have either included patients admitted with acute heart failure $(2,11)$ or highly selected study populations; $(12,13)$ or have not adjusted analyses for natriuretic peptide levels. $(14,15)$ Ning et al. conducted a meta-analysis of 13 studies and found a significant association between high TSH and all-cause mortality, but found that the association was absent in the three studies (containing 407 hypothyroid patients) which adjusted for natriuretic peptide levels.(16)

There are few data on the relation between thyroid function and prognosis in unselected ambulatory patients with chronic heart failure, so we therefore explored the relation in a large, well characterised cohort of patients with heart failure with different degrees of left ventricular systolic dysfunction.

\section{METHODS}

\section{Study population}

This study was a retrospective analysis of patients included in the HullLifeLab registry. Between March 2000 and March 2018, we enrolled 6782 consecutive patients, referred by both primary and secondary care physicians, to a community heart failure clinic serving a local population of $\sim 600,000$ people. Some patients had no prior diagnosis of heart failure and were treatment naive, therefore requiring initiation of guideline-recommended therapy; many others had a pre-existing diagnosis of 
$\mathrm{HF}$ and had already been initiated on treatment that might, however, require optimisation. Heart failure was defined as the presence of characteristic symptoms and/or signs, plus objective evidence of cardiac dysfunction at rest; either left ventricular systolic dysfunction (LVSD) mild or worse, defined as HeFREF, or normal left ventricular systolic function and N-terminal pro-B-type natriuretic peptide (NT-proBNP) >125 ng/l, defined as HeFNEF.(17) Patients with constrictive pericarditis, more than moderate valve regurgitation or stenosis, hypertrophic cardiomyopathy or infiltrative cardiomyopathy were excluded. Patients were also excluded if they had missing data on echocardiography or thyroid function tests (Figure 1).

\section{Thyroid hormone sampling and definition of subclinical thyroid dysfunction}

Thyroid hormones were measured during a patient's initial visit to the heart failure clinic. TSH and fT4 were both measured simultaneously by the hospital's biochemistry department using the Beckman Coulter UniCel DxI 800 Access Immunoassay method (Beckman Coulter, Miami, USA). Thyroid status was defined using reference ranges provided by the kit manufacturer. Euthyroidism was defined as a TSH level of 0.35-4.70mIU/l, subclinical hypothyroidism as a TSH level $>4.70 \mathrm{mIU} / \mathrm{L}$ with normal free T4 (7.8-21.0pmol/1), and subclinical hyperthyroidism as a TSH level < $0.35 \mathrm{mIU} / \mathrm{L}$ with normal free T4. Overt hypothyroidism was defined as TSH>4.70 mIU/L with decreased free T4, and overt hyperthyroidism was defined as $\mathrm{TSH}<0.35 \mathrm{mIU} / \mathrm{L}$ with raised free T4. $(18,19)$

\section{Data collection}

All patients had a full medical history, physical examination, and electrocardiogram. Ischaemic heart disease was identified by any medical history of acute coronary syndrome (ACS), percutaneous coronary intervention $(\mathrm{PCI})$ or coronary artery bypass surgery $(\mathrm{CABG})$, or a diagnosis of myocardial ischaemia based on invasive or noninvasive diagnostic tests. Chronic obstructive pulmonary disease and hypertension were identified by a clinical history of the diagnoses recorded in patients' notes. Blood was taken for standard haematology and biochemistry profiles and NT-proBNP. Body mass index (BMI) was calculated as weight in kilograms / (height in meters) squared.

Patients had an echocardiogram performed by an experienced sonographer using a Vivid 5, 7, or 9 Scanner (GE, Fairfield, USA). All patients had left ventricular systolic function evaluated by visual assessment recorded (ranging from normal to severely impaired), and left ventricular ejection fraction was calculated where possible using the Simpson method.(20) 


\section{Endpoints and follow up}

Patients were followed up until $12^{\text {th }}$ March 2018. The primary outcome was all-cause mortality. A secondary outcome was the composite endpoint of mortality or hospitalisation with heart failure. Our hospital is responsible for all acute medical services in the region. We have access to all primary and secondary care records. Outcome is censored at the point of last medical contact in primary or secondary care. Data regarding deaths were collected from the hospital's electronic systems, entered into a dedicated database, and stored on a secure National Health Service server.

\section{Statistical analysis}

Categorical results are presented as number and percentages, normally distributed continuous data as mean \pm standard deviation (SD), and non-normally distributed continuous variables as median with interquartile ranges (IQR). Continuous variables were compared using the independent t-test or analysis of variance (ANOVA) as appropriate. Assumptions of ANOVA were met. Categorical variables were tested using the chi-squared test and Fisher's exact test. Since there were so few patients with overt thyroid disease, we grouped those with overt and subclinical thyroid disease for further analyses. Cox proportional hazards analyses were used to assess prognostic associations, the proportionality of hazards assumption was verified. Variables with a P value less than 0.1 in univariable analysis qualified for inclusion in the multivariable analysis. We divided patients into quintiles based on baseline TSH (Q1-Q5). Separate analyses for increasing TSH as a predictor of mortality were performed in patients with low TSH excluded (Q2-Q5), and high TSH excluded (Q1Q4). Hazard ratios (HRs) with 95\% confidence intervals (CI) are reported. Kaplan-Meier cumulative survival plots were constructed to illustrate the results. A P value less than 0.05 (two-tailed) was considered statistically significant. Statistical analyses were performed using Statview 5.0 (Abacus Concepts, Berkeley, California), SPSS 25 (SPSS Inc., Chicago, Illinois) and STATA 14.0 (StataCorp, College Station, Texas).

\section{Ethics approval}

The study conformed to the principles outlined in the Declaration of Helsinki and was approved by relevant ethical bodies. All subjects gave their written informed consent for their data to be used for research. 


\section{RESULTS}

The flow of patients through the study is shown in Figure 1.

\section{Distribution of TSH and baseline characteristics by thyroid status}

The distribution of TSH was positively skewed (Figure 2). Most patients were euthyroid; 6.3\% ( $n=312$ ) were hypothyroid, of whom only 12 had overt hypothyroidism. A much smaller proportion of patients had hyperthyroidism, with only $0.9 \%$ having overt hyperthyroidism. Baseline characteristics of patients by thyroid status are shown in Table 1. Patients with thyroid dysfunction were more likely to be female, had lower systolic and diastolic blood pressure, had lower haemoglobin levels, and were more likely to be taking amiodarone, a diuretic, or a mineralocorticoid receptor antagonist compared to euthyroid patients. Patients with hyperthyroidism had higher NT-proBNP and higher NYHA class than either euthyroid or hyperthyroid patients. Hypothyroid patients also had a lower serum sodium, and a higher prevalence of AF than euthyroid patients.

Table S1 shows the patients divided by heart failure phenotype. There was no difference in TSH between the groups, but hypothyroidism was more common amongst patients with HeFREF. There was no relation between severity of LVSD and TSH (Figure S1).

\section{Thyroid status and outcome}

\section{Mortality}

During a median follow up of 4.6 (IQR 1.8-7.5) years, 2879 (58\%) patients died.

In univariable analysis, patients with either hypothyroidism or hyperthyroidism had a higher all-cause mortality than euthyroid patients (Table S2). There was a U-shaped relation between TSH and outcome (Figure 3). When patients with a low TSH (Q1) were excluded, increasing TSH was associated with increased mortality. When patients with a high TSH (Q5) were excluded, there was no association between TSH and mortality. Figure 4 shows Kaplan-Meier plots for patients stratified by thyroid status. Both hyperthyroid and hypothyroid patients had lower survival compared to euthyroid patients.

The statistical significance of the association between thyroid dysfunction (hypothyroidism, hyperthyroidism, and increasing TSH) and mortality disappeared in multivariable analysis (Figure 5). The three strongest independent predictors of adverse outcome were age, increasing NT-proBNP and higher NYHA class. 
Amongst only those patients with HeFREF, increasing TSH was associated with increased mortality in univariable analysis (Table S3), but the association disappeared in multivariable analysis (Figure 5). Amongst only those patients with HeFNEF, a weak but significant association between increasing TSH and mortality persisted in multivariable analysis (Table S4, Figure 5).

\section{Mortality and heart failure hospitalisation}

During follow up, 2150 patients were hospitalised with heart failure and 3607 (72\%) patients either died or were hospitalised with heart failure.

In univariable analysis, hypothyroid patients had a significantly worse prognosis than euthyroid patients (Table S5). Hyperthyroidism was not a predictor of the composite endpoint. When patients with a low TSH (Q1) were excluded, increasing TSH was associated with worse prognosis. When patients with a high TSH (Q5) were excluded, there was no association between TSH and prognosis.

The association between hypothyroidism and worse prognosis disappeared in multivariable analysis (Figure 5). The three strongest predictors of the composite outcome were increasing NT-proBNP, age, and higher NYHA class.

Amongst only those patients with HeFREF, increasing TSH was associated with significantly worse prognosis in univariable analysis, but this significant association disappeared in multivariable analysis (Table S6). Amongst only those patients with HeFNEF, a weak but significant association between increasing TSH and worse prognosis persisted in multivariable analysis (Table S7).

We found no strong correlations between TSH and other independent predictors of adverse outcome (Table S8).

\section{Impact of thyroxine replacement on results}

Thyroxine was taken by $8.7 \%$ of patients at baseline. Thyroxine use was most common in patients with hyperthyroidism, followed by hypothyroid patients, and was least common in euthyroid patients. Thyroxine use was also more common amongst patients with HeFNEF compared to HeFREF (Table S1). Patients taking thyroxine replacement were older, more likely to be female, had higher BMI, lower diastolic blood pressure and lower haemoglobin (Table S9).

In the analysis of patients who were not receiving thyroxine replacement; increasing TSH was associated with reduced mortality in multivariable analysis when patients with a high TSH (Q5) were excluded, but not when patients with a low TSH (Q1) were excluded (Table S10). 


\section{DISCUSSION}

We have shown that although thyroid dysfunction is related to outcome in patients with chronic heart failure, the association disappears when adjustment is made for established prognostic variables such as age, NT-proBNP, and NYHA class. The strength of our study is that we have investigated a large, unselected cohort of consecutive patients for the vast majority of whom we also had available NTproBNP levels. Ours is the first study to examine the prognostic significance of thyroid dysfunction in patients who have been followed for longer than 10 years.

Our results differ to those from many previous studies $(12,14-16,21)$ but are in agreement with studies which adjusted for natriuretic peptides in their analyses. (16) The largest previous analysis which adjusted for natriuretic peptides was of the CORONA (Controlled Rosuvastatin Multinational Study in Heart Failure) trial population, which found that thyroid status was not an independent predictor of outcome after correction for NT-proBNP in 4750 patients with HeFREF followed for 3 years.(13)

We found that the prevalence of hypothyroidism was 6.3\%, consistent with both reports from the general population (between 4 and 9\% (5,22)) and from populations of patients with heart failure (3.5$16.4 \%(13,14))$. For hyperthyroidism, the prevalence in our cohort was $3.8 \%$, compared to a reported prevalence of $1-2 \%(5,22)$ in the general population, and $1-5 \%$ in populations of patients with heart failure. $(12,13)$

Hypothyroid patients had higher NT-proBNP, more severe symptoms, and a higher prevalence of comorbidities than euthyroid patients, presumably explaining (at least in part) the relation between hypothyroidism and worse outcome in univariable analysis. We found similar, but smaller, differences between euthyroid patients and hyperthyroid patients.

\section{Thyroid Hormones and NT-proBNP}

The association between thyroid function and outcome disappeared when we corrected for NTproBNP, consistent with the CORONA analyses.(13) Thyroid hormones may directly stimulate NTproBNP expression and secretion, and thus thyroid dysfunction could impact on NT-proBNP levels.(23) Alternatively, worsening heart failure can lead to downregulation of thyroid hormone signalling.(24) Our results support the latter explanation, since the highest NT-proBNP levels were in the hypothyroid group, and adjustment for NT-proBNP removed the association between thyroid dysfunction and worse prognosis, NT-proBNP is a marker of heart failure severity, not a marker of increasing TSH. 


\section{Thyroid Dysfunction in Heart Failure with Normal Ejection Fraction}

Ours is the first study to examine the prognostic significance of thyroid dysfunction in a large population of patients with HeFNEF. We found thyroxine use was more common among patients with HeFNEF compared to those with HeFREF. This finding may be explained by shared population characteristics between HeFNEF and hypothyroidism. Hypothyroid patients and patients with HeFNEF are more likely to be older, female, and to have a higher burden of comorbidities when compared to euthyroid patients and patients with HeFREF respectively.(5) Hypothyroidism may also cause some of the symptoms typically associated with HeFNEF such as fatigue.

We also found a weak, but significant association between increasing TSH and both mortality and the composite endpoint in patients with HeFNEF. Overt hypothyroidism can lead to diastolic dysfunction through downregulation of the sarcoplasmic/endoplasmic reticulum calcium ATPase 2 (SERCA2) gene.(1) Reduced SERCA2 activity leads to a slower decrease in diastolic calcium, therefore increasing the duration of cardiomyocyte relaxation. Thyroid hormone effects on cardiac relaxation do not explain the differences in the results between ejection fraction subgroups as most patients with HeFREF also have diastolic dysfunction.

\section{Thyroxine Replacement Therapy in Heart Failure}

Thyroxine use was most common amongst patients with hyperthyroidism, suggesting that they were previously hypothyroid and had received excessive treatment. When patients receiving thyroxine replacement were removed from the analysis, there was a weak but significant association between low TSH and mortality. It may be that there is a weak relation between endocrine hyperthyroidism and mortality which was concealed in our primary analysis due to the inclusion of patients with iatrogenic hyperthyroidism.

The role of thyroxine replacement in subclinical hypothyroidism is unclear. The TRUST (Thyroid Hormone Therapy for Older Adults with Subclinical Hypothyroidism) trial found that thyroxine replacement provided no benefit in 737 patients older than 65 years with subclinical hypothyroidism.(25) According to European Thyroid Association guidelines, thyroxine replacement may be considered in patients over 70 years old, with a TSH $\geq 10 \mathrm{mIU} / \mathrm{L}$, and either symptoms of hypothyroidism or high cardiovascular risk.(26) There have been no trials investigating the role of thyroxine replacement in patients with heart failure and subclinical hypothyroidism.

\section{Study Limitations}

Our study has the limitations of a retrospective, observational study design. Our data are a snapshot at a single time-point, and we were not able to study the significance of changing TSH levels over time. We do not routinely measure T3 levels, so we were unable to investigate the significance of low-T3 
syndrome. Ejection fraction measurements were missing in a proportion of patients; visual assessment of systolic dysfunction was available in all. Some might not accept an NT-proBNP $>125 \mathrm{pg} / \mathrm{mL}$ as diagnostic for HeFNEF, although it is consistent with the recent European Society of Cardiology guidelines. The diagnosis of HeFNEF can be difficult in many cases. While we tried to adjust for clinically relevant variables, it is impossible to adjust for all variables that might affect outcome.

\section{CONCLUSION}

Although thyroid dysfunction is associated with worse survival in patients with chronic heart failure, it is not an independent predictor of mortality. 


\section{FUNDING}

NAS was supported by a grant from The Academy of Medical Sciences and the Wellcome Trust.

\section{ACKNOWLEDGEMENTS}

None. 


\section{REFERENCES}

1. Razvi S, Jabbar A, Pingitore A, Danzi S, Biondi B, Klein I, Peeters R, Zaman A, Iervasi G. Thyroid Hormones and Cardiovascular Function and Diseases. J Am Coll Cardiol 2018; 71:178196.

2. Hayashi T, Hasegawa T, Kanzaki H, Funada A, Amaki M, Takahama H, Ohara T, Sugano Y, Yasuda S, Ogawa H, Anzai T. Subclinical hypothyroidism is an independent predictor of adverse cardiovascular outcomes in patients with acute decompensated heart failure. ESC Hear Fail 2016; 3:168-76.

3. Klein I, Danzi S. Thyroid disease and the heart. Circulation 2007; 116:1725-35.

4. Biondi B, Cooper DS. The Clinical Significance of Subclinical Thyroid Dysfunction Endocr Rev 2008; 29:76-131.

5. GJ, Manowitz NR, Mayor G, Ridgway EC. The Colorado thyroid disease prevalence study. Arch Intern Med 2000; 160:526-34.

6. Rodondi N, den Elzen WPJ, Bauer DC, Cappola AR, Razvi S, Walsh JP, Asvold BO, Iervasi G, Imaizumi M, Collet TH, Bremner A, Maisonneuve P, Sgarbi JA, Khaw KT, Vanderpump MP, Newman AB, Cornuz J, Franklyn JA, Westendorp RG, Vittinghoff E, Gussekloo J, Thyroid Studies Collaboration. Subclinical Hypothyroidism and the Risk of Coronary Heart Disease and Mortality. JAMA 2010; 304:1365.

7. Chaker L, Baumgartner C, den Elzen WPJ, Ikram MA, Blum MR, Collet T-H, Bakker SJL, Dehghan A, Drechsler C, Luben RN, Hofman A, Portegies MLP, Medici M, Iervasi G, Stott DJ, Ford I, Bremner A, Wanner C, Ferrucci L, Newman AB, Dullaart RP, Sgarbi JA, Graziano C, Maciel RMB, Westendorp RG, Jukema JW, Imaizumi M, Franklyn JA, Bauer DC, Walsh JP, Razvi S, Khaw K-T, Cappola AR, Völzke H, Franco OH, Gussekloo J, Rodondi N, Peeters RP, Thyroid Studies Collaboration. Subclinical Hypothyroidism and the Risk of Stroke Events and Fatal Stroke: An Individual Participant Data Analysis. J Clin Endocrinol Metab 2015; 100:218191.

8. Rodondi N, Bauer DC, Cappola AR, Cornuz J, Robbins J, Fried LP, Ladenson PW, Vittinghoff E, Gottdiener JS, Newman AB. Subclinical Thyroid Dysfunction, Cardiac Function, and the Risk of Heart Failure. J Am Coll Cardiol 2008; 52:1152-9.

9. Collet T-H, Gussekloo J, Bauer DC, den Elzen WPJ, Cappola AR, Balmer P, Iervasi G, Ãsvold BO, Sgarbi JA, Völzke H, Gencer B, Maciel RM, Molinaro S, Bremner A, Luben RN, Maisonneuve P, Cornuz J, Newman AB, Khaw KT, Westendorp RG, Franklyn JA, Vittinghoff E, Walsh JP, Rodondi N, Thyroid Studies Collaboration. Subclinical Hyperthyroidism and the Risk of Coronary Heart Disease and Mortality. Arch Intern Med 2012; 172:799-809.

10. Vanderpump MP, Tunbridge WM, French JM, Appleton D, Bates D, Clark F, Grimley Evans J, Hasan DM, Rodgers H, Tunbridge F, Young ET. The incidence of thyroid disorders in the community: a twenty-year follow-up of the Whickham Survey. Clin Endocrinol (Oxf) 1995; 43:55-68.

11. Frey A, Kroiss M, Berliner D, Seifert M, Allolio B, Güder G, Ertl G, Angermann CE, Störk S, Fassnacht M. Prognostic impact of subclinical thyroid dysfunction in heart failure. Int $J$ Cardiol 2013; 168:300-5. 
12. Mitchell JE, Hellkamp AS, Mark DB, Anderson J, Johnson GW, Poole JE, Lee KL, Bardy GH. Thyroid Function in Heart Failure and Impact on Mortality J Am Coll Cardiol HF 2013; 1:48-55.

13. Perez AC, Jhund PS, Stott DJ, Gullestad L, Cleland JGF, van Veldhuisen DJ, Wikstrand J, Kjekshus J, McMurray JJ. Thyroid-Stimulating Hormone and Clinical Outcomes. J Am Coll Cardiol HF 2014; 2:35-40.

14. Chen S, Shauer A, Zwas DR, Lotan C, Keren A, Gotsman I. The effect of thyroid function on clinical outcome in patients with heart failure. Eur J Heart Fail 2014; 16:217-26.

15. Kannan L, Shaw PA, Morley MP, Brandimarto J, Fang JC, Sweitzer NK, Cappola TP, Cappola AR. Thyroid Dysfunction in Heart Failure and Cardiovascular Outcomes. Circ Hear Fail 2018; 11:e005266

16. Ning N, Gao D, Triggiani V, Iacoviello M, Mitchell JE, Ma R, Zhang Y, Kou H. Prognostic Role of Hypothyroidism in Heart Failure A Meta-Analysis. Medicine (Balt) 2015; 94:e1159

17. Ponikowski P, Voors AA, Anker SD, Bueno H, Cleland JGF, Coats AJS, Falk V, GonzalezJuanatey JR, Harjola VP, Jankowska EA, Jessup M, Linde C, Nihoyannopoulos, Parissis JT, Pieske B, Riley JP, Rosano GMC, Ruilope LM, Ruschitzka F, Rutten FH, van der Meer P. 2016 ESC Guidelines for the diagnosis and treatment of acute and chronic heart failure. Eur Heart $J$ 2016; 37:2129-2200

18. Surks MI, Ortiz E, Daniels GH, Sawin CT, Col NF, Cobin RH, Franklyn JA, Hershman JM, Burman KD, Denke MA, Gorman C, Cooper RS, Weissman NJ. Subclinical Thyroid Disease. JAMA 2004; 291:228

19. Gencer B, Collet T-H, Virgini V, Bauer DC, Gussekloo J, Cappola AR, Nanchen D, den Elzen WP, Balmer P, Luben RN, Iacoviello M, Triggiani V, Cornuz J, Newman AB, Khaw KT, Jukema JW, Westendorp RG, Vittinghoff E, Aujesky D, Rodondi N, Thyroid Studies Collaboration. Subclinical thyroid dysfunction and the risk of heart failure events: an individual participant data analysis from 6 prospective cohorts. Circulation 2012; 126:1040-9

20. Otterstad JE. Measuring left ventricular volume and ejection fraction with the biplane Simpson's method. Heart 2002; 88:559-60

21. Iacoviello M, Guida P, Guastamacchia E, Triggiani V, Forleo C, Catanzaro R, Cicala M, Basile M, Sorrentino S, Favale S. Prognostic Role of Sub-Clinical Hypothyroidism in Chronic Heart Failure Outpatients. Curr Pharm Des 2008; 14:2686-2092

22. Hollowell JG, Staehling NW, Flanders WD, Hannon WH, Gunter EW, Spencer CA, Braverman LE. Serum TSH, T4, and Thyroid Antibodies in the United States Population (1988 to 1994): National Health and Nutrition Examination Survey (NHANES III). J Clin Endocrinol Metab 2002; 87:489-99

23. Schultz M, Faber J, Kistorp C, Jarlov A, Pedersen F, Wiinberg N, Hildebrandt P. N-terminal-proB-type natriuretic peptide (NT-pro-BNP) in different thyroid function states. Clin Endocrinol (Oxf) 2004; 60:54-9

24. Grais IM, Sowers JR. Thyroid and the Heart. Am J Med 2014; 127:691-8

25. Stott DJ, Rodondi N, Kearney PM, Ford I, Westendorp RGJ, Mooijaart SP, Sattar N, Aubert CE, Aujesky D, Bauer DC, Baumgartner C, Blum MR, Browne JP, Byrne S, Collet TH, Dekkers OM, den Elzen WPJ, Du Puy RS, Ellis G, Feller M, Floriani C, Hendry K, Hurley C, Jukema JW, Kean S, Kelly M, Krebs D, Langhorne P, McCarthy G, McCarthy V, McConnachie A, McDade M, 
Messow M, O’Flynn A, O’Riordan D, Poortvliet RKE, Quinn TJ, Russell A, Sinnott C, Smit JWA, Van Dorland HA, Walsh KA, Walsh EK, Watt T, Wilson R, Gussekloo J, TRUST Study Group. Thyroid Hormone Therapy for Older Adults with Subclinical Hypothyroidism. $N$ Engl $J$ Med 2017; 376:2534-44

26. Pearce SHS, Brabant G, Duntas LH, Monzani F, Peeters RP, Razvi S, Wemeau JL. 2013 ETA Guideline: Management of Subclinical Hypothyroidism. Eur Thyroid J 2013; 2:215-28 


\section{TABLES}

\begin{tabular}{|c|c|c|c|c|}
\hline \multirow[t]{2}{*}{ Variable } & \multicolumn{3}{|c|}{ Thyroid-Stimulating Hormone } & \multirow[t]{2}{*}{$P$ value } \\
\hline & $(>4.70)^{\star}$ & $(0.35-4.70)$ & $(<0.35)^{\dagger}$ & \\
\hline & $\mathrm{n}=312$ & $\mathrm{n}=4491$ & $\mathrm{n}=189$ & \\
\hline Age (years) & $74 \pm 10$ & $73 \pm 11$ & $74 \pm 10$ & 0.14 \\
\hline Women & $41 \%$ & $37 \%$ & $58 \%$ & $<0.0001$ \\
\hline Thyroid Stimulating Hormone (mU/l) & $6.40(5.40-8.50)$ & $1.70(1.20-2.50)$ & $0.15(0.09-0.27)$ & $\mathrm{N} / \mathrm{A}$ \\
\hline Serum free T4 $(\mathrm{pmol} / \mathrm{l})$ & $13.0(11.0-15.0)$ & $\mathrm{N} / \mathrm{A}$ & $18.0(16.0-21.0)$ & $\mathrm{N} / \mathrm{A}$ \\
\hline NT-proBNP (ng/l) & $1974(885-4296)$ & $1105(438-2545)$ & $1118(483-2860)$ & $<0.0001$ \\
\hline Body mass index $\left(\mathrm{kg} / \mathrm{m}^{2}\right)$ & $28.5 \pm 6.4$ & $28.8 \pm 6.1$ & $28.5 \pm 6.8$ & 0.51 \\
\hline Heart rate (bpm) & $77 \pm 18$ & $75 \pm 18$ & $77 \pm 16$ & 0.12 \\
\hline Atrial fibrillation & $47 \%$ & $34 \%$ & $31 \%$ & $<0.0001$ \\
\hline Systolic blood pressure $(\mathrm{mmHg})$ & $135 \pm 27$ & $140 \pm 26$ & $139 \pm 25$ & 0.0007 \\
\hline Diastolic blood pressure $(\mathrm{mmHg})$ & $78 \pm 15$ & $79 \pm 14$ & $75 \pm 13$ & 0.004 \\
\hline NYHA Class I & $19 \%$ & $22 \%$ & $20 \%$ & 0.38 \\
\hline Class II & $41 \%$ & $48 \%$ & $47 \%$ & 0.06 \\
\hline Class III/IV & $40 \%$ & $30 \%$ & $33 \%$ & 0.0008 \\
\hline Heart failure with reduced ejection fraction & $68 \%$ & $60 \%$ & $58 \%$ & 0.009 \\
\hline Heart failure with normal ejection fraction & $32 \%$ & $40 \%$ & $42 \%$ & 0.009 \\
\hline Ischemic heart disease & $44 \%$ & $47 \%$ & $39 \%$ & 0.08 \\
\hline Hypertension & $37 \%$ & $41 \%$ & $45 \%$ & 0.29 \\
\hline Diabetes mellitus & $22 \%$ & $24 \%$ & $27 \%$ & 0.39 \\
\hline Chronic obstructive pulmonary disease & $8 \%$ & $9 \%$ & $10 \%$ & 0.82 \\
\hline Diuretic & $80 \%$ & $72 \%$ & $76 \%$ & 0.002 \\
\hline ACEi or ARB & $69 \%$ & $70 \%$ & $69 \%$ & 0.94 \\
\hline$\beta$-Blocker & $61 \%$ & $59 \%$ & $59 \%$ & 0.73 \\
\hline Mineralocorticoid receptor antagonist & $31 \%$ & $20 \%$ & $24 \%$ & $<0.0001$ \\
\hline Statin & $45 \%$ & $51 \%$ & $48 \%$ & 0.07 \\
\hline Thyroxine & $22 \%$ & $6 \%$ & $48 \%$ & $<0.0001$ \\
\hline Amiodarone & $3 \%$ & $1 \%$ & $2 \%$ & 0.001 \\
\hline Haemoglobin (g/dl) & $12.8 \pm 1.9$ & $13.3 \pm 1.8$ & $12.7 \pm 1.5$ & $<0.0001$ \\
\hline Creatinine $(\mu \mathrm{mol} / \mathrm{l})$ & $110(88-145)$ & $99(81-124)$ & $95(78-129)$ & $<0.0001$ \\
\hline Urea $(\mathrm{mmol} / \mathrm{l})$ & $6.05(4.70-8.40)$ & $7.00(5.40-9.50)$ & $7.30(5.20-10.40)$ & $<0.0001$ \\
\hline Sodium (mmol/l) & $137 \pm 3$ & $138 \pm 3$ & $138 \pm 4$ & $<0.0001$ \\
\hline Potassium (mmol/l) & $4.4 \pm 0.5$ & $4.4 \pm 0.5$ & $4.3 \pm 0.5$ & 0.36 \\
\hline
\end{tabular}

*Included 12 patients with overt hypothyroidism (TSH $>4.7 \mathrm{mU} / \mathrm{f}, \mathrm{fT} 4<7.8 \mathrm{pmol} / \mathrm{l})$, of whom 2 patients were on thyroxine replacement.

†Included 43 patients with overt hyperthyroidism ( $\mathrm{TSH}<0.35, \mathrm{fT} 4>21.0 \mathrm{pmol} / \mathrm{l})$, of whom 5 patients were on thyroxine replacement.

Table 1. Demographics, clinical characteristics and pharmacological treatment of patients with heart failure according to thyroid status 


\section{FIGURES}

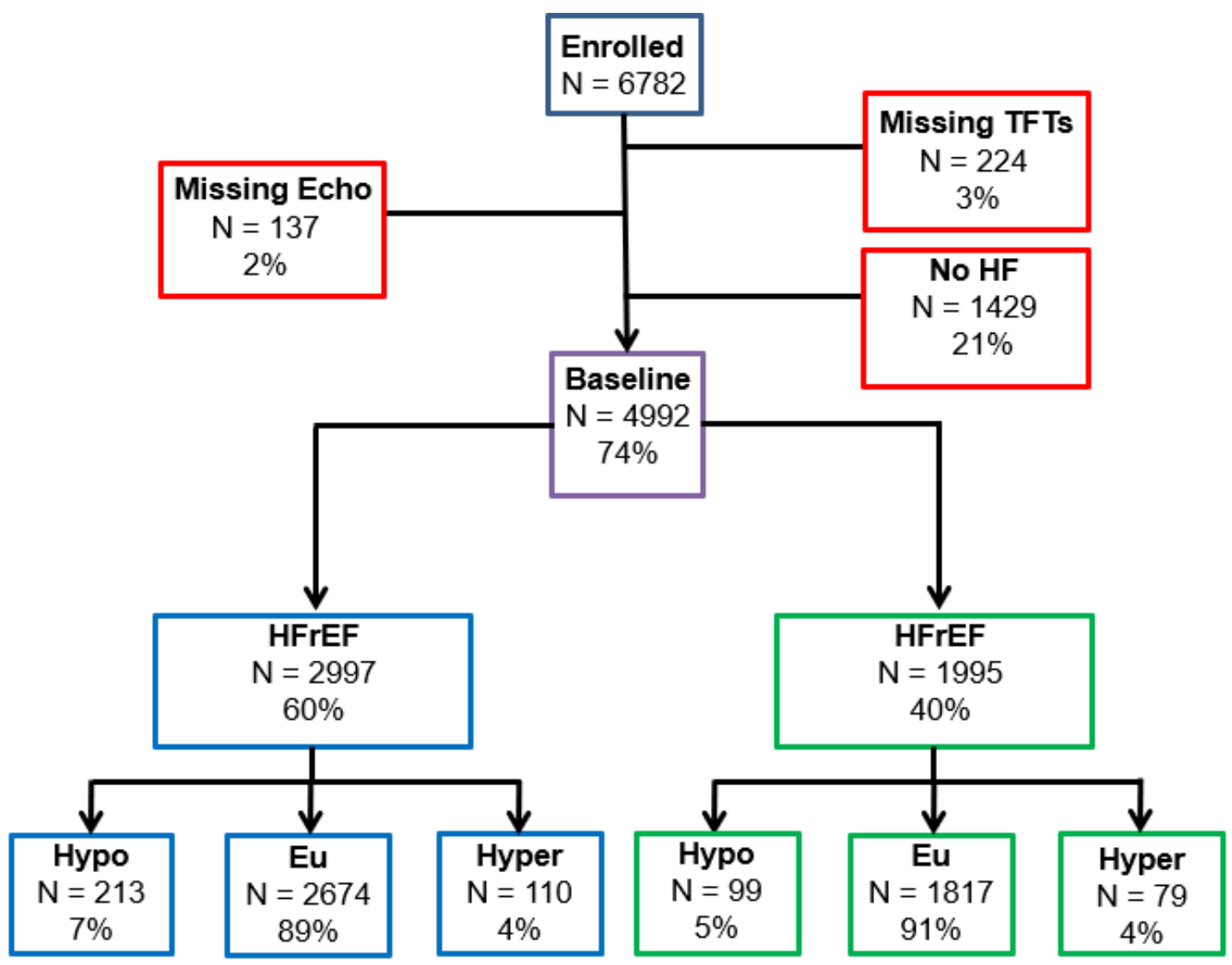

\section{Figure 1. CONSORT diagram}

Echo, echocardiogram; TFTs, thyroid function tests; HF, heart failure; HeFREF, heart failure with reduced ejection fraction; HeFNEF, heart failure with normal ejection fraction; Hypo, hypothyroid; Eu, euthyroid; Hyper, hyperthyroid 


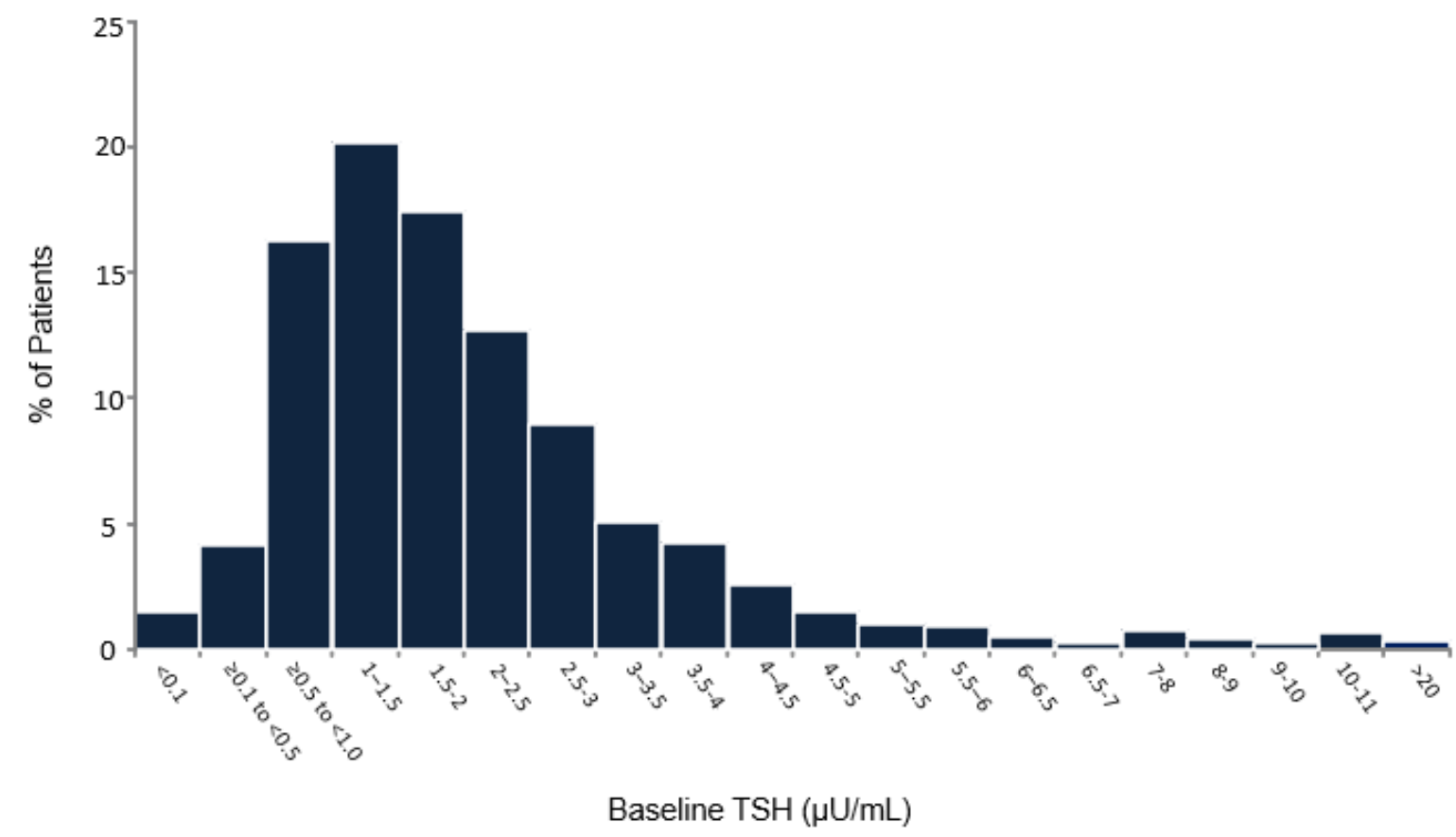

Figure 2. Distribution of TSH values

Distribution of TSH values at baseline in the patient cohort. Intervals on the right of the graph include a wider range of values due to less data. TSH, thyroid stimulating hormone. 


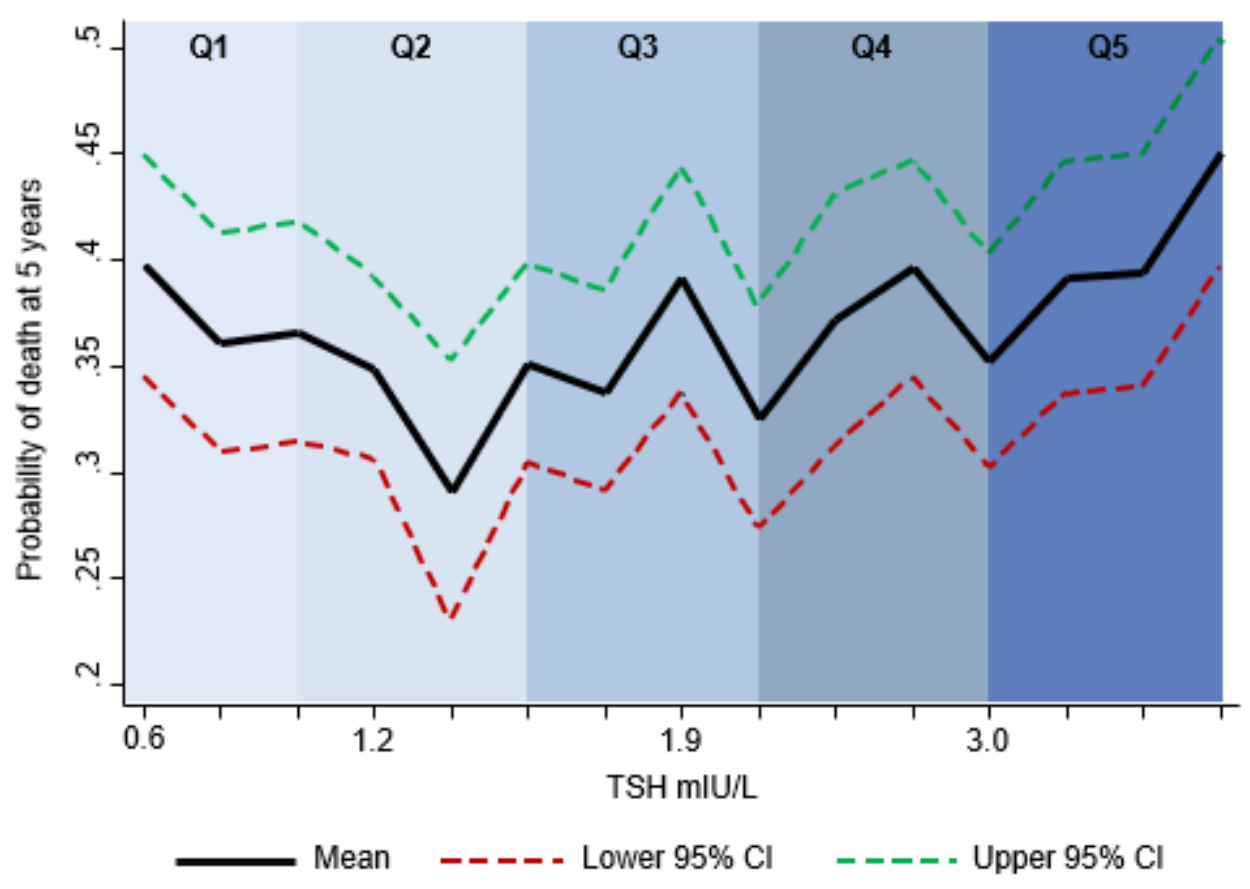

Figure 3. U-shaped Relation between TSH and probability of death at 5 years

The population was divided into quintiles based on TSH values, denoted by blue shaded areas on the figure. 


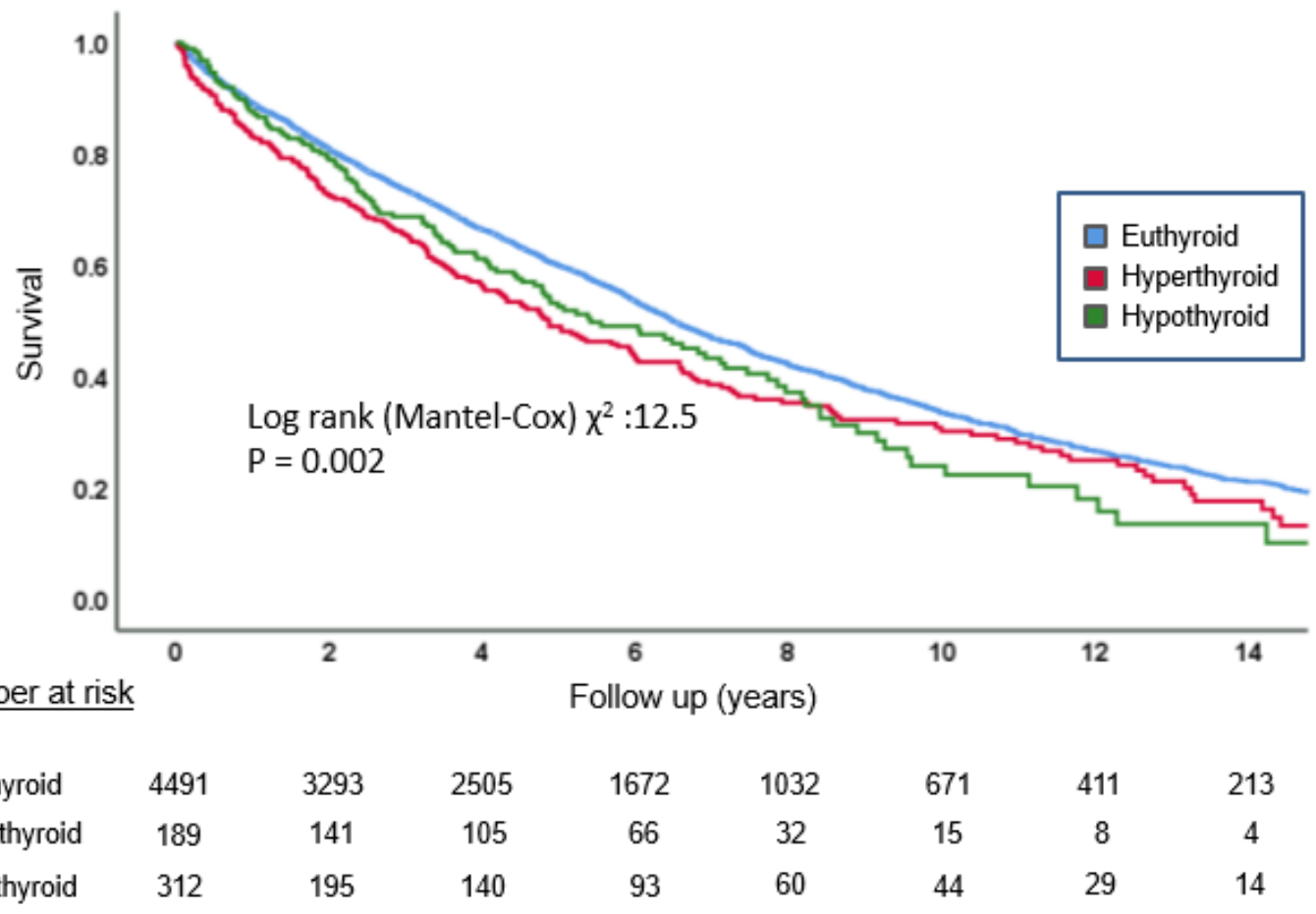

Figure 4. Kaplan-Meier survival curve for all-cause mortality stratified by thyroid status 


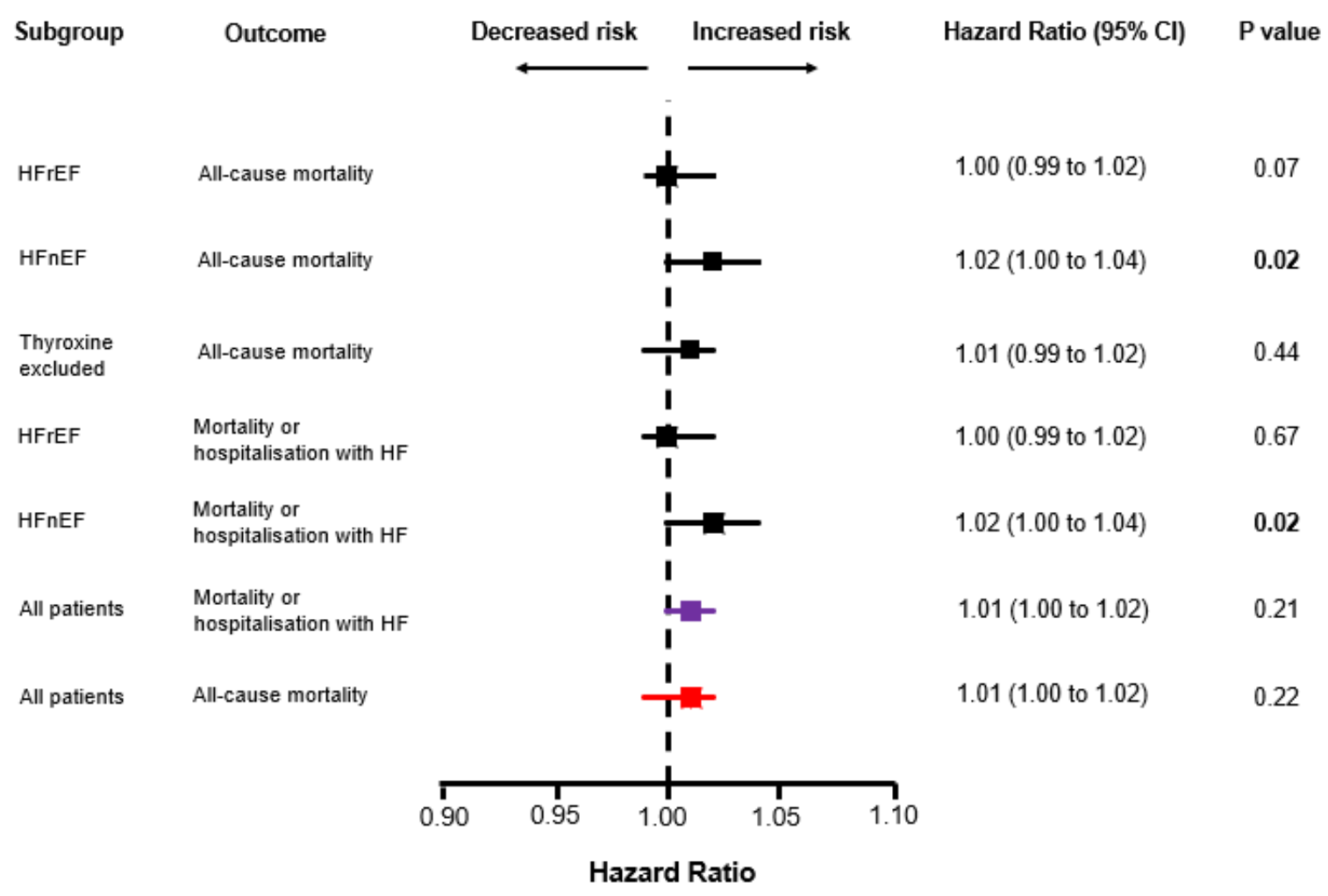

Figure 5. Multivariable analysis for the association between increasing TSH and outcome in patients stratified by ejection fraction classification and in patients who were not receiving thyroxine replacement

Hazard Ratio represents the increased risk associated with a $1 \mathrm{mIU} / \mathrm{l}$ increase in TSH. HeFREF, heart failure with reduced ejection fraction; HeFNEF, heart failure with normal ejection fraction. 


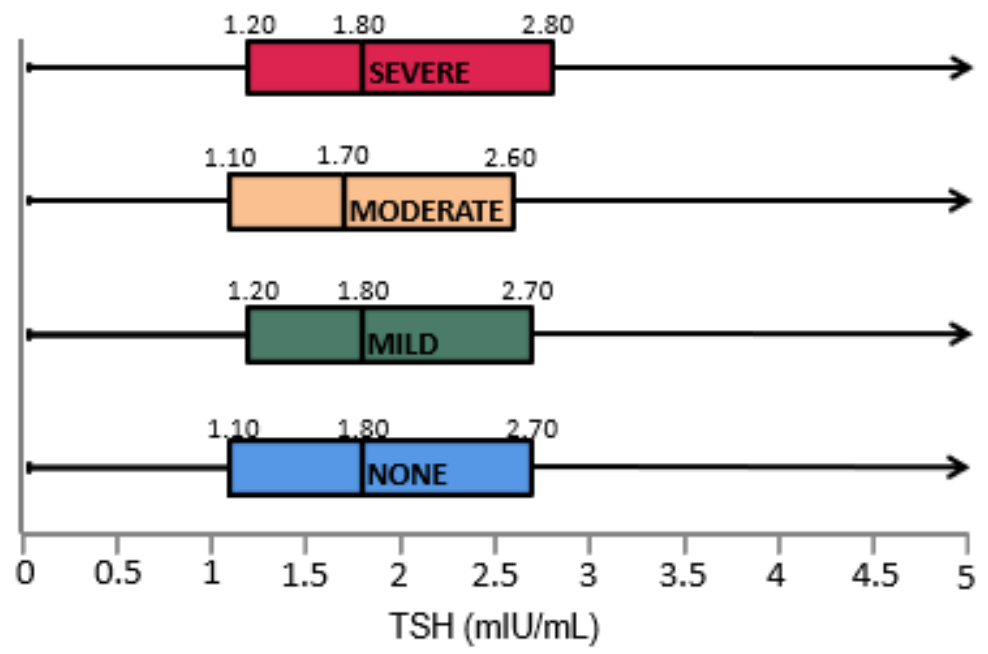

Figure S1. Box and whisker plot of baseline TSH in patients grouped by severity of left ventricular systolic dysfunction

Values shown are median, and upper and lower quartiles. Arrows on the right signify an upper range of $\mathrm{TSH}>5 \mathrm{mIU} / \mathrm{L}$. 